\title{
The use of ice to cool the concrete mix in the construction of massive structures
}

\author{
Nikolay Aniskin ${ }^{1}$, Trong Chuc Nguyen ${ }^{2 *}$, and Anh Kiet Bui ${ }^{3}$ \\ ${ }^{1}$ National Research Moscow State University of Civil Engineering, d. 26, YaroslavskoeShosse, \\ Moscow, 129337, Russian Federation \\ ${ }^{2}$ Le Quy Don Technical University, Hanoi 100000, Vietnam \\ ${ }^{3}$ Ho Chi Minh City Open University, Vietnam
}

\begin{abstract}
This article proposes a formula to determine the required amount of ice to partially replace the water in the concrete mix to control the initial temperature of the concrete mix and reduce possible cracking. The formula was created based on the principle of energy balance in the heat transfer process. At the same time, the obtained results were compared with the other methods. Besides, an example of the calculation for a concrete block during the construction was performed. The maximum temperature and temperature difference in mass concrete obtained depend significantly on the initial temperature of the concrete mixture. The research results and the proposed techniques can be used in the practical design of mass concrete structures.
\end{abstract}

\section{Introduction}

The construction of massive concrete structures such as dams, foundations, and bridge supports requires the use of a large volume of cement as a binder. In such structures, which have a small value of the ratio of its surface area and volume, the process of removing the heat released during hydration from the inside to the outside of the surface of the structure slows down, and the risk of thermal cracking increases [1-3]. Advanced concrete technology has created high-performance concrete with a large cement content, which increases the curing process and also shortens the construction schedules. At the same time, when placing concrete with a large amount of cement, it will lead to a temperature peak and the temperature difference between the center and the surface of the concrete block will increase. Therefore, this, in turn, leads to thermal cracking at an early age [4-6].

To minimize the formation of thermal cracks by controlling the main factors that influence the temperature regime in mass concrete structures. These include the consumption of cement and its heat release, the time of concrete placement, the thickness of the concrete placement, the initial temperature of the concrete mixture, etc. [7-10].

In the practice of building mass concrete, measures commonly used to prevent the formation of thermal cracks in mass concrete structures include [11]:

+ use of low-heat cement or replace cement with some other material (fly ash, slag, etc.) to reduce the degree of exothermic heating of the concrete mixture being laid [12];

\footnotetext{
*Corresponding author: ntchuc.mta198@gmail.com
} 
+ use chemical additives to slow down and reduce heat generation in the hydration of cement [13];

+ the choice of the moment of concrete placement (both the season and the time of day). In particular, placing concrete at night or in the early morning has several advantages - in particular, reducing the exposure to solar radiation in the early hours after concrete placement; placing concrete in the cold season in this sense is also often preferable $[14,15]$;

+ using a cooling pipe system to reduce the temperature inside the concrete block [16, 17];

+ use surface insulation to reduce the temperature difference between the central zone and the concrete block's surface (it can be used during construction both in winter and summer). When built in the winter, the surface insulation works to prevent rapid cooling of the concrete block surface. In contrast, when built in the summer, the surface insulation prevents the warming of the concrete block surface [11];

+ reducing the thickness of the poured layer can reduce the maximum temperature in the concrete block. However, reducing the pour layer thickness can affect the construction progress and project cost [11].

All the above measures to reduce the maximum temperature inside the concrete block require a detailed study of the economic feasibility analysis [11].

There are many ways to reduce the initial temperature of concrete mixes, such as lowering the aggregate temperature, using liquid nitrogen to reduce the concrete mix, using cool water, or using ice instead of part of the water.

Cooling a concrete mixture with liquid nitrogen is one of the most effective means to reduce the temperature of the concrete mixture to $(30-35)^{\circ} \mathrm{C}$. However, this is a costly method due to special equipment requirements to spray liquid nitrogen gas into the concrete mix. The above method is used only in extreme cases. The most economical and easiest to apply method is to cool by water and especially to partially replace the water with ice. In this case, an important task is to correctly determine the required amount of ice. Several researchers' work is devoted to determining the amount of ice required to obtain the value of the required temperature for the concrete mixture [11].

In this paper, use the principle of energy balance to determine the amount of ice required to partially replace the water and obtain the initial temperature of the desired concrete mixture. A formula is proposed for determining the required amount of ice to obtain a concrete mixture with the required initial temperature. At the same time, the study results are compared with the recommendations of other authors. The research results show good agreement with laboratory experiments, and previously obtained results indicate the reliability of the results. Therefore, the study results can be used when designing and controlling the formation of thermal cracks in mass concrete structures.

\section{Materials and methods}

This research is carried out based on the basic laws of physics. In particular, the law of conservation of energy in the heat transfer process has been applied. The numerical calculations were performed by Midas software with a program algorithm based on the theory of heat conduction and convection heat transfer.

a. Determination of the initial temperature for the concrete mix

The available methods for determining the initial temperature of concrete mixtures depend on the composition and the temperature of the components. This is a simple method and is based on the energy balance theory. Following the standards of the Japan Concrete Institute [18] "Concrete Mass Cracking Control Guide 2016", the formula for determining the initial temperature of a concrete mixture is as follows: 


$$
T_{o}=\frac{c_{1}\left(m_{c} T_{c}+m_{a} T_{a}+m_{s} T_{s}\right)+c_{2} m_{\mathrm{w}} T_{\mathrm{W}}}{c_{1}\left(m_{c}+m_{a}+m_{s}\right)+c_{2} m_{\mathrm{w}}},
$$

where: $\mathrm{m}_{\mathrm{i}(\mathrm{i}=\mathrm{c}, \mathrm{a}, \mathrm{s}, \mathrm{w})}$ is mass of the $\mathrm{i}$-th component of the concrete mixture per $1 \mathrm{~m}^{3}$ of concrete mixture, $\mathrm{kg} / \mathrm{m}^{3}$ (c, a, s, w are symbols for cement, coarse aggregate, sand, and water, respectively); $\mathrm{T}_{\mathrm{i}(\mathrm{i}=\mathrm{c}, \mathrm{a}, \mathrm{s}, \mathrm{w})}$ is the temperature of the $\mathrm{i}$-th aggregate in the concrete mixture, ${ }^{\circ} \mathrm{C} ; \mathrm{c}_{1}$ is specific heat capacity of cement and aggregate (they are approximately equal in value), $\mathrm{kcal} /\left(\mathrm{kg} .{ }^{\circ} \mathrm{C}\right) ; \mathrm{c}_{2}$ is the specific heat capacity of water, $\mathrm{kcal} /\left(\mathrm{kg} .{ }^{\circ} \mathrm{C}\right)$.

Taking into account that $\mathrm{c}_{\mathrm{c}}=\mathrm{c}_{\mathrm{a}}=\mathrm{c}_{\mathrm{s}}=\mathrm{c}_{1} \approx 0.2 \mathrm{kcal} /\left(\mathrm{kg} .{ }^{\circ} \mathrm{C}\right)$, and $\mathrm{c}_{2} \approx 1.0 \mathrm{kcal} /\left(\mathrm{kg} .{ }^{\circ} \mathrm{C}\right)$, formula (1) can be written as follows [18]:

$$
T_{o}=\frac{0.2\left(m_{c} T_{c}+m_{a} T_{a}+m_{s} T_{s}\right)+m_{\mathrm{w}} T_{\mathrm{w}}}{0.2\left(m_{c}+m_{a}+m_{s}\right)+m_{\mathrm{w}}},
$$

The referenced standard states that to lower the temperature of concrete by $1^{\circ} \mathrm{C}$, it is usually necessary to lower the temperature of the cement, aggregate, or mixing water by about $8^{\circ} \mathrm{C}, 2^{\circ} \mathrm{C}$, and $4^{\circ} \mathrm{C}$, respectively.

When using ice to cool water, the temperature drop $\Delta \mathrm{T}$ of a concrete mixture is determined by the formula (3) [18]:

$$
\Delta T=\frac{m_{i c e}\left\{79.6+\left(T_{o}-0\right)\right\}}{0.2\left(m_{c}+m_{a}+m_{s}\right)+m_{\mathrm{w}}} E_{f},
$$

where: $\mathrm{m}_{\text {ice }}$ is mass of ice $\left(\mathrm{kg} / \mathrm{m}^{3}\right)$; $\mathrm{E}_{\mathrm{f}}$ is cooling efficiency (can be taken as $\left.0.7-0.8\right)$.

However, the above formula does not fully consider the nature of the energy transfer process. In addition, in the case of using ice to cool the water, the amount of ice needed to reduce the initial temperature of the concrete mixture has not been determined.

That takes an effort to determine the amount of ice required to obtain a given initial temperature of the concrete mix. In this case, it is also necessary to ensure the $\mathrm{W} / \mathrm{C}$ ratio required to obtain concrete of the desired composition.

b. Method for determining the amount of ice required to cool the concrete mixture We consider the thermal balance of a concrete mixture. Symbols, masses of each component, and their thermal properties are shown in Table 1.

Let's denote by $\mathrm{x}$ the unknown amount of ice in kilograms used to cool the concrete mixture. Then the required amount of water at the accepted value of the water-cement ratio $\mathrm{W} / \mathrm{C}$ will be equal to $\left(\alpha \times \mathrm{m}_{\mathrm{c}}-\mathrm{x}\right)$. Let's take the ice temperature equal to $0^{\circ} \mathrm{C}$. We take the specific heat of melting of ice $\lambda=81.26(\mathrm{kcal} / \mathrm{kg})$ [18]. The initial temperature of the concrete mixture after mixing is denoted $\mathrm{T}_{0}$. Each of the $\mathrm{i}$ components of the concrete mixture, before mixing, has a temperature of $\mathrm{T}_{\mathrm{i}}$, respectively.

Table 1. Mixture proportions of concrete

\begin{tabular}{|c|c|c|c|c|c|c|}
\hline Parameters & $\mathrm{W} / \mathrm{C}$ & $\begin{array}{c}\text { Cemen } \\
\mathrm{t}\end{array}$ & $\begin{array}{c}\text { coarse } \\
\text { aggregate }\end{array}$ & Sand & water & ice \\
\hline Weight, $\mathrm{kg}$ & $\alpha$ & $\mathrm{m}_{\mathrm{c}}$ & $\mathrm{m}_{\mathrm{a}}$ & $\mathrm{m}_{\mathrm{s}}$ & $\begin{array}{c}\alpha \times \mathrm{m}_{\mathrm{c}}- \\
\mathrm{x}\end{array}$ & $\mathrm{x}$ \\
\hline Specific heat, $\mathrm{kcal} /\left(\mathrm{kg} .{ }^{\circ} \mathrm{C}\right)$ & - & $\mathrm{c}_{\mathrm{c}}$ & $\mathrm{c}_{\mathrm{a}}$ & $\mathrm{c}_{\mathrm{s}}$ & $\mathrm{c}$ & - \\
\hline Temperature, ${ }^{\circ} \mathrm{C}$ & & $\mathrm{T}_{\mathrm{c}}$ & $\mathrm{T}_{\mathrm{a}}$ & $\mathrm{T}_{\mathrm{s}}$ & $\mathrm{T}_{\mathrm{w}}$ & 0 \\
\hline
\end{tabular}


Then the amount of thermal energy when the temperature of the components decreases to the initial temperature of concrete $\mathrm{T}_{0}$, will be equal to:

$$
Q_{A}=\sum_{i} c_{i} m_{i}\left(T_{i}-T_{o}\right),
$$

Substituting the symbols according to Table 1, we obtain equation (5):

$$
Q_{A}=c_{c} m_{c}\left(T_{c}-T_{o}\right)+c_{a} m_{a}\left(T_{a}-T_{o}\right)+c_{s} m_{s}\left(T_{s}-T_{o}\right)+c_{\mathrm{w}}\left(\alpha m_{c}-x\right)\left(T_{\mathrm{w}}-T_{o}\right)
$$

The heat required for thawing the ice and the transition of the temperature of the formed water from $0^{\circ} \mathrm{C}$ to the temperature $\mathrm{T}_{\mathrm{o}}$ will be:

$$
Q_{B}=\lambda \cdot m_{i c e}+c_{\mathrm{w}} m_{i c e}\left(T_{o}-0\right)=\lambda \cdot x+c_{\mathrm{w}} \cdot x \cdot T_{o}
$$

According to the principle of heat balance, equality can be written: $\mathrm{Q}_{\mathrm{A}}=\mathrm{Q}_{\mathrm{B}}$, or

$$
c_{c} m_{c}\left(T_{c}-T_{o}\right)+c_{a} m_{a}\left(T_{a}-T_{o}\right)+c_{s} m_{s}\left(T_{s}-T_{o}\right)+c_{\mathrm{w}}\left(\alpha m_{\mathrm{w}}-x\right)\left(T_{\mathrm{w}}-T_{o}\right)=\lambda x+c_{\mathrm{w}} x T_{o}
$$

From equation (7), the amount of ice required to partially replace water to obtain the initial temperature of the $T_{0}$ the concrete mixture was determined and presented as equation (8).

$$
x=\frac{c_{c} m_{c}\left(T_{c}-T_{o}\right)+c_{a} m_{a}\left(T_{a}-T_{o}\right)+c_{s} m_{s}\left(T_{s}-T_{o}\right)+c_{\mathrm{w}} \alpha m_{\mathrm{w}}\left(T_{\mathrm{w}}-T_{o}\right)}{\lambda+c_{\mathrm{w}} T_{\mathrm{w}}}
$$

Assuming that the temperature of the components of the concrete mixture is taken approximately equal to the air temperature $\left(\mathrm{T}_{\mathrm{c}}=\mathrm{T}_{\mathrm{a}}=\mathrm{T}_{\mathrm{s}}=\mathrm{T}_{\mathrm{w}}=\mathrm{T}_{\text {air }}\right)$ and $\mathrm{c}_{\mathrm{c}}=\mathrm{c}_{\mathrm{a}}=\mathrm{c}_{\mathrm{s}} \approx 0.2$ $\mathrm{kcal} /\left(\mathrm{kg} .{ }^{\circ} \mathrm{C}\right), \mathrm{c}_{\mathrm{w}} \approx 1.0 \mathrm{kcal} /\left(\mathrm{kg} .{ }^{\circ} \mathrm{C}\right)$. Equation (8) can be written simply as follows:

$$
x=\frac{\left[0.2\left(m_{c}+m_{a}+m_{s}\right)+\alpha m_{c}\right]\left(T_{\text {air }}-T_{o}\right)}{\lambda+T_{\text {air }}}
$$

\section{Results and Discussion}

a. Determine the amount of ice required to cool the concrete mixture

The proposed formula was applied to estimate the temperature control of the concrete mass due to the initial temperature of the concrete mixture. The composition of the concrete mixture used for constructing the massif is presented in Table 2 [19]. The average temperature of the air $\mathrm{T}_{\text {air }}=20^{\circ} \mathrm{C}$. Determine the amount of ice required to obtain the initial temperature of the concrete mixture is $16^{\circ} \mathrm{C}$.

Table 2.The composition of the concrete mix

\begin{tabular}{|c|c|c|c|c|c|}
\hline \multirow{2}{*}{ Mixing proportions } & W/C & $\begin{array}{c}\text { Cement, } \\
\mathrm{kg} / \mathrm{m}^{3}\end{array}$ & $\begin{array}{c}\text { Aggregate, } \\
\mathrm{kg} / \mathrm{m}^{3}\end{array}$ & $\begin{array}{c}\text { Water, } \\
\mathrm{kg} / \mathrm{m}^{3}\end{array}$ & $\begin{array}{c}\text { ice, } \\
\mathrm{kg} / \mathrm{m}^{3}\end{array}$ \\
\cline { 2 - 6 } & 0.5 & 350 & 1814 & $175-\mathrm{x}$ & $\mathrm{x}$ \\
\hline
\end{tabular}

Using the resulting formula (9), the required amount of ice water is obtained:

$$
x=\frac{\left[0.2\left(m_{c}+m_{a}+m_{s}\right)+\alpha m_{c}\right]\left(T_{\text {air }}-T_{o}\right)}{\lambda+T_{\text {air }}}=\frac{[0.2(350+1814)+0.5 \times 350](20-16)}{81.26+20}=24.01
$$


Thus, the volume of water at the initial temperature is equal to the air temperature $\left(20^{\circ} \mathrm{C}\right)$, is $175-24.01=150.99 \mathrm{~kg}$.

\section{Let us determine the water temperature under the conditions considered.}

The amount of heat required to reduce the water temperature from $20^{\circ} \mathrm{C}$ to $\mathrm{T}_{\mathrm{w}}$ is:

$$
Q_{1}=c_{\mathrm{w}} m_{\mathrm{w}}\left(T_{\mathrm{air}}-T_{\mathrm{w}}\right)=150.99\left(20-T_{\mathrm{w}}\right)
$$

The amount of heat required to melt ice and increase its temperature from $0^{\circ} \mathrm{C}$ to $\mathrm{T}_{\mathrm{w}}$ is:

$$
Q_{2}=\lambda . m_{i c e}+c_{\mathrm{w}} m_{i c e}\left(T_{\mathrm{w}}-0\right)=81.26 \times 24.01+24.01 T_{\mathrm{w}}=1951.05+24.01 T_{\mathrm{w}}
$$

According to the principle of energy balance $\mathrm{Q}_{1}=\mathrm{Q}_{2}$ :

$$
150.99\left(20-T_{\mathrm{w}}\right)=1951.05+24.01 T_{\mathrm{w}},
$$

then we receive it $\mathrm{T}_{\mathrm{w}}=6.1^{\circ} \mathrm{C}$.

With similar data, according to published research results, the water temperature after mixing with ice is $5^{\circ} \mathrm{C}[19]$.

The difference between the author's results and the previous study is explained by the lack of details of the experiment performed in the study [19]. In addition, in this study, the approximate values of the specific heat capacities $\left(c_{i}\right)$ and the melting point of ice $(\lambda)$ were taken, which could lead to a deviation of the results obtained. In addition, heat loss is inevitable when interacting with the environment.

To compare with other research results, the calculations were performed according to the recommendations of the standards of the Japanese Institute of Concrete [18]. According to this recommendation, the reduced temperature of the concrete mixture after mixing with ice is:

$$
\Delta T=\frac{m_{i c e}\left\{79.6+\left(T_{o}-0\right)\right\}}{0.2\left(m_{c}+m_{a}+m_{s}\right)+m_{\mathrm{w}}} E_{f}=\frac{24.01\{79.6+20\}}{0.2(350+1814)+150.99} \times 0.8=3.24^{\circ} \mathrm{C}
$$

According to the method described in this work $-\Delta \mathrm{T}=20-16=4^{\circ} \mathrm{C}$.

Differences between the calculation results can be explained by differences in the parameters in the calculation.

$b$. The influence of the initial temperature of the concrete mixture on the temperature regime in mass concrete

In this paper, consider the effect of the initial temperature of the concrete mixture on the temperature regime of a concrete block with the size of $8 \mathrm{~m} \times 6 \mathrm{~m} \times 3 \mathrm{~m}$. This concrete block is placed on the foundation with the dimensions of $16 \mathrm{~m} \times 12 \mathrm{~m} \times 4 \mathrm{~m}$. The calculation diagram and finite element model are shown in Figure 1 (1/4 meshed model of finite element). The characteristics of concrete and foundation accepted in the calculations are presented in Table 3. Wooden formwork with a thickness of $2.5 \mathrm{~cm}$, and horizontal surface insulation was used. 

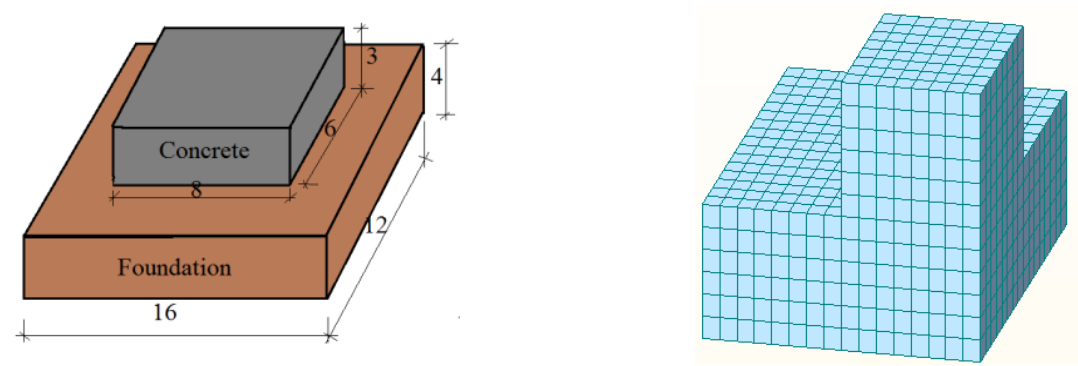

Fig. 1. Design block diagram and FEM mesh

Table 3. Calculated physical characteristics of materials

\begin{tabular}{|c|c|c|c|}
\hline \multirow{2}{*}{ No } & \multirow{2}{*}{ Characteristics, units } & \multicolumn{2}{|c|}{ Values } \\
\cline { 3 - 4 } & Thermal conductivity coefficient, $\mathrm{W} /\left(\mathrm{m} .{ }^{\circ} \mathrm{C}\right)$ & Concrete & Foundation \\
\hline 1 & Specific heat, $\mathrm{kJ} /\left(\mathrm{kg} .{ }^{\circ} \mathrm{C}\right)$ & 2.60 & 2.00 \\
\hline 2 & Density of material, $\mathrm{kg} / \mathrm{m}^{3}$ & 0.95 & 0.84 \\
\hline 3 & Modulus of elasticity, $\mathrm{N} / \mathrm{m}^{2}$ & 2400 & 2650 \\
\hline 4 & Convective heat transfer coefficient $/\left(\mathrm{m}^{2} .{ }^{\circ} \mathrm{C}\right)$ & 2.6 & 14.00 \\
\hline 5 & The coefficient of linear thermal expansion & $2.7 \times 10^{10}$ & $1.8 \times 10^{10}$ \\
\hline 6 & Poisson's ratio & $1 \times 10^{-6}$ & $1 \times 10^{-5}$ \\
\hline 7 & \multicolumn{2}{c}{0.18} & 0.20 \\
\hline
\end{tabular}

Equivalent convective heat transfer coefficient on a surface with wooden formwork is $\mathrm{h}_{\mathrm{eq}}=2.6 \mathrm{~W} /\left(\mathrm{m}^{2} .{ }^{\circ} \mathrm{C}\right)[20]$. The convective heat transfer coefficient of the surface with insulation is $0.66 \mathrm{~W} /\left(\mathrm{m}^{2}{ }^{\circ} \mathrm{C}\right)$. Consider the composition of the concrete mix is presented in Table 2. The average temperature of the air $\mathrm{T}_{\text {air }}=20^{\circ} \mathrm{C}$. Let us determine the amount of ice required for the initial temperature of the concrete mixture equal to $5,10,12$, and $16^{\circ} \mathrm{C}$.

Table 4. The amount of ice required to cool the concrete

\begin{tabular}{|c|c|c|c|c|c|}
\hline Initial concrete temperature $T_{o}{ }^{\circ} \mathrm{C}$ & 5 & 10 & 12 & 16 & 20 \\
\hline ice $-\mathrm{x}, \mathrm{kg} / \mathrm{m}^{3}$ & 90.04 & 60.02 & 48.02 & 24.01 & 0 \\
\hline Water, $\mathrm{kg} / \mathrm{m}^{3}$ & 84.96 & 114.98 & 126.98 & 150.99 & 175 \\
\hline $\begin{array}{c}\text { \% of the volume of ice instead of } \\
\text { water }\end{array}$ & $51.45 \%$ & $34.29 \%$ & $27.44 \%$ & $13.72 \%$ & $0 \%$ \\
\hline
\end{tabular}

According to the proposed formula Equation (9), the amount of ice required to obtain the initial temperature of the concrete mixture is determined for each design case. The calculation results are presented in Table 4.

Thus, to lower the temperature of the concrete mixture of the considered composition from $20^{\circ} \mathrm{C}$ to $5^{\circ} \mathrm{C}$, it is necessary to replace $51.45 \%$ of the volume of water with ice (which is $90 \mathrm{~kg}$ per cubic meter).

With the help of Midas, civil software for the calculated domain was considered, and different values of the initial temperature of the concrete mixture. The maximum temperature, the temperature difference between the center and the surface of the concrete block have been determined. The obtained results are shown in Table 5, and the graph is presented in Figure 2. 
Table 5. Influence of the initial temperature of the concrete mixture on the maximum temperature and temperature drops

\begin{tabular}{|c|c|c|c|c|c|}
\hline $\mathrm{T}_{\mathrm{o}}$ & 5 & 10 & 12 & 16 & 20 \\
\hline $\mathrm{T}_{\max }$ & 57.91 & 63.66 & 65.86 & 70.16 & 74.33 \\
\hline$\Delta \mathrm{T}_{1}=$ between center and side surface & 17.17 & 19.71 & 20.62 & 22.37 & 24.09 \\
\hline$\Delta \mathrm{T}_{2}=$ between center and top surface & 3.03 & 3.65 & 4.05 & 4.39 & 4.85 \\
\hline Time to reach maximum temperature, $\mathrm{h}$ & 168 & 132 & 120 & 96 & 84 \\
\hline
\end{tabular}

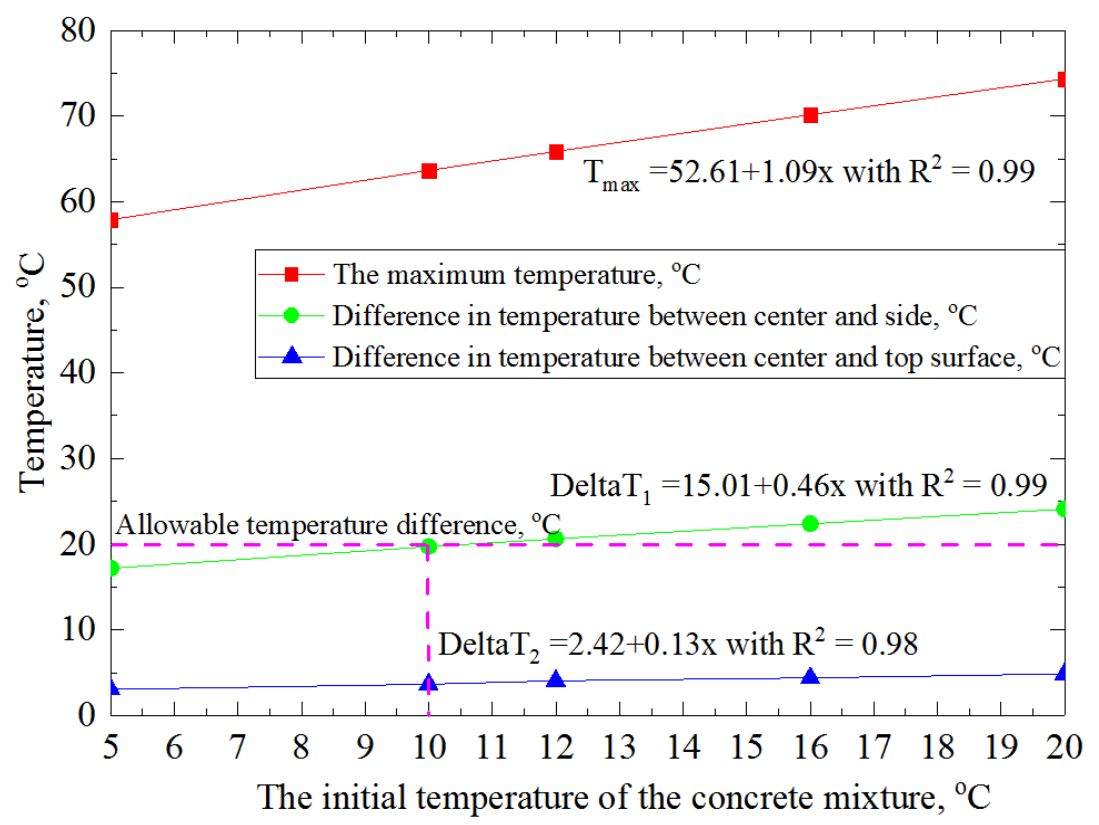

Fig. 2. Change in maximum temperature and temperature differences depending on the initial temperature of the concrete

\section{Conclusions}

Based on the results obtained, the following should be noted:

(1) When using cooling water to prepare concrete mix is a fairly affordable and costeffective method to reduce heat generation in mass concrete structures. The effect can be increased by replacing a certain amount of water with ice.

(2) By adjusting the amount of ice, it is possible to obtain the initial temperature of the concrete mixture, the maximum temperature, and the temperature difference to reach the desired value. This avoids the formation of temperature cracks.

(3) A simple formula is proposed to determine the required amount of ice with the given parameters and concrete composition.

(4) Use Midas software to determine the maximum temperature and the temperature difference in mass concrete. The results obtained show that the maximum temperature values, the temperature difference depend on the initial temperature of the concrete mixture. The relationship of the maximum temperature, the temperature difference with the concrete mixture initial temperature is linear. To ensure that the temperature difference between the center and the surface of the concrete block does not exceed $20^{\circ} \mathrm{C}$ (according to the requirements of crack resistance), the initial temperature of the concrete mixture under the conditions under consideration should not exceed $10^{\circ} \mathrm{C}$. That means, under consideration, the minimum required amount of ice water is $60 \mathrm{~kg} / \mathrm{m}^{3}$. 
(5) The initial temperature of the concrete mixture affects the time of occurrence of the maximum temperature in the mass concrete structure. So, for the considered case, the time of occurrence of the maximum temperature at an initial concrete temperature of $10^{\circ} \mathrm{C}$ is 132 hours after laying and at $20^{\circ} \mathrm{C}-84$ hours. In addition, when the initial temperature of the concrete mixture decreases, the strength development of the concrete may decrease. This should be considered in the technological process.

(6) The proposed method to calculate the required amount of ice for cooling the constructed concrete mass can be used in the design of the technology for concreting massive structures.

\section{References}

1. SP41.13330.2012 2012 Concrete and reinforced concrete structures of hydraulic structures (Moscow: Ministry of Regional Development of Russia) 115 p (In Russian)

2. ACI 207.1R-96 1996 Mass Concrete (Reported by ACI Committee 207)

3. ACI 207. 1R-05 2005 Guide to Mass Concrete (Reported by ACI Committee 207)

4. Aniskin N A, Nguyen T C, Hoang Q L 2018 MATEC Web of Conferences 251, 02014

5. Aniskin N A, Nguyen T C, Bryansky I A, Dam H H 2018 Vestnik MGSU 13(11)14071418

6. Tang Hao, Cai De-Suo, Yang Li 2013 Applied Mechanics and Materials 300-301 1584-1588

7. Jin Keun Kim, Kook Han Kim, Joo Kyoung Yang 2001 Computers and Structures 79 163-171

8. Kuzmanovic V, Savic L, Mladenovic N 2013 Journal of Thermal Stresses 36(2) 112134

9. Joo-Kyoung Yang, Yun Lee, Jin-Keun Kim 2011 Journal of Advanced Concrete Technology 9(1) 103-114

10. Li B, Wang Z, Jiang Y, Zhu Z 2018 Advances in Mechanical Engineering 10(1) 1-15

11. Aniskin N A, Nguyen T C 2020 Vestnik MGSU 15(3) 380-398

12. Kim S G 2010 Effect of heat generation from cement hydration on mass concrete placement (Graduate Theses and Dissertations, Iowa State University)

13. Wenqiang Xu, Sheng Qiang, Zhengkai Hu, Bingyong Ding, Bingyong Yang 2020 Advances in Civil Engineering 17p

14. Aniskin N A, Nguyen T C, Le D A 2020 Power Technology and Engineering 54 1-6

15. Dadiani N Z 2018 Power Technology and Engineering 6 49-54

16. Nguyen T C, Nguyen T S, Nguyen Q V, Do T M D 2020 Tructural integrity and life 20(2) 131-135

17. Wen C L, Wan L C, Hui Q Y, Tian X Y, Wang J 2016 Applied Science 110(6) 18p

18. Japan Concrete Institute 2016 Guidelines for Control of Cracking of Mass Concrete 2016. (Japan) $302 \mathrm{p}$

19. Barbara Klemczak, Agnieszka Knoppik-Wróbel2011 Architecture civil engineering environment 4 47-58

20. Aniskin N A, Nguyen T C 2020 Magazine of civil Engineering 99(7) 11p. 